\title{
PENGARUH METODE PEMBELAJARAN DAN MOTIVASI BELAJAR TERHADAP KEMAMPUAN MENULIS ANEKDOT PADA SISWA KELAS X MADRASAH ALIYAH SWASTA DI KOTA DEPOK
}

\author{
Titi Sukarti \\ Jurusan Perhotelan dan Perjalanan Wisata, Akademi Pariwisata Jakarta \\ Email : titisukarti@gmail.com
}

\begin{abstract}
Abstrak
Tujuan penelitian ini adalah untuk mengetahui pengaruh metode pembelajaran terhadap kemampuan menulis teks anekdot siswa MA Swasta Kota Depok. Pengaruh motivasi belajar terhadap kemampuan menulis teks anekdot siswa MA swasta Kota Depok. Pengaruh interaktif metode pembelajaran dan motivasi belajar terhadap kemampuan menulis teks anekdot siswa MA swasta Kota Depok. Metode penelitian yang digunakan adalah metode eksperimen. Populasi dalam penelitian ini adalah seluruh siswa kelas X MA swasta di kecamatan Sukmajaya kota Depok, yaitu MA Nur Al Zahrah dan MA Al Jihad pada tahun ajaran 2016-2017, dimana kapasitas tiap kelas antara 3440 siswa. Sedangkan jumlah sampel yaitu undian (jumlah kelas paralel dari sekolah yang dijadikan populasi) 65 siswa. Hasil penelitian menunjukkan : 1) Terdapat pengaruh yang signifikan metode pembelajaran terhadap kemampuan menulis teks anekdot siswa MA Nur Al Zahrah. 2) Terdapat pengaruh yang signifikan motivasi belajar terhadap kemampuan menulis teks anekdot siswa di MA Nur Al Zahrah. 3) Terdapat pengaruh interaksi yang signifikan metode pembelajaran dan motivasi belajar terhadap kemampuan menulis teks anekdot siswa MA Nur Al Zahrah. Dampak yang diperoleh dari metode ini yaitu Proses pembelajaran mengalami peningkatan pada aspek perhatian, keaktifan, keantusiasan, dan kekondusifan siswa menuju arah lebih baik. memberikan motivasi kepada siswa agar mau menulis teks anekdot melalui metode pembelajaran yang interaktif sehingga siswa bisa lebih aktif dalam mengembangkan ide dalam penulisan teks anekdot.
\end{abstract}

Kata kunci : Pembelajaran Genius Learning, Motivasi Belajar, Kemampuan Menulis Anekdot

\begin{abstract}
The purpose of this research is to find the influence of a method of learning in the ability of the students write the text of anecdotes private Madrasah Aliyah Depok city. The influence of the motivation to study write the text of anecdotes students in the ability of the private Madrasah Aliyah Depok city .The influence of interactive method of learning and the motivation to study write the text of anecdotes students in the ability of the private Madrasah Aliyah Depok city .Research methods that were used is the experimental methods are .It is a whole research population in a student of class $\mathrm{x}$ ma private in Sukmajaya Depok city, namely Madrasah Aliyah Nur Al Zahrah and Madrasah Aliyah Al Jihad in the academic year 2016-2017, where the capacity of each individual class between the 34-40 students. While the total sample that is the draw (parallel from the total number of classrooms to school population) 65 students. The research results show: 1) Significant influence in the ability of the method of learning write the text of anecdotes students MA Nur Al Zahrah. 2) Significant influence in the ability of the the motivation to study write the text of anecdotes students in MA Nur Al Zahrah. 3) There are the influence of the interaction that significant a method of learning and the motivation to study of the ability of students write the text of anecdotes MA Nur Al Zahrah. The impact of this method that is obtained from the teaching process increases significantly every aspects of attention, active, exited, and conducive students toward the direction of the better. To motivate your students in order to want to write the text of anecdotes through a method of interactive learning and so students can be more active in developing ideas in writing text anecdote.
\end{abstract}

Keywords: Genius Learning, Motivation Learning, Ability write anecdotes 


\section{PENDAHULUAN}

Peningkatan kualitas pembelajaran merupakan salah satu peningkatan mutu pendidikan secara keseluruhan. Upaya peningkatan mutu pendidikan adalah bagian terpadu dari upaya peningkatan kualitas manusia, baik aspek kemampuan, kepribadian maupun tanggung jawab sebagai warga negara. Ahli-ahli kependidikan telah menyadari mutu pendidikan sangat tergantung pada kualitas guru dan kualitas pembelajarannya sehingga peningkatan secara rasional. Proses pendidikan saat ini diibaratkan terlalu mementingkan aspek kognitif dan mengabaikan kreativitas [1].

Keterampilan menulis merupakan keterampilan yang bersifat mekanistis, keterampilan menulis tidak mungkin dikuasai hanya melalui teori, tetapi dilaksanakan melalui latihan dan praktik yang teratur sehingga menghasilkan tulisan yang tersusun baik [2]. Keterampilan menulis menghendaki penguasaan berbagai unsur kebahasaan dan unsur di luar bahasa itu sendiri yang akan menjadi karangan. Salah satu kompetensi dasar yang diusung dalam kurikulum 2013 untuk Sekolah Menengah Atas atau Aliyah adalah tentang memproduksi teks anekdot secara lisan maupun tulisan dengan mengambil spesifikasi menulis teks anekdot. Dalam kurikulum tersebut dinyatakan bahwa anekdot bertujuan menceritakan suatu kejadian yang tidak biasa dan lucu. Sementara itu munculnya teks anekdot sebagai teks yang diajarkan dalam mata pelajaran Bahasa Indonesia baru disampaikan secara tersurat dalam kurikulum 2013. Sesuai dengan prinsip pembelajaran Bahasa Indonesia dalam kurikulum tersebut yakni berbasis teks. Teks anekdot menjadi salah satu teks yang wajib dipelajari siswa. Hanya saja teks anekdot baru dikenalkan melalui jenjang SMA/MA/SMK.
Kenyataan menunjukkan, kemampuan menulis siswa belum memadai. Hal ini terlihat pada pembelajaran kemampuan menulis dengan kompetensi inti memproduksi teks anekdot di MA swasta Depok. Hasil tulisan siswa kelas X MA swasta Depok tergolong masih rendah. Selain itu, jumlah siswa yang berhasil mencapai dan melampaui KKM kurang dari $75 \%$. Berdasarkan pengamatan awal penelitian, rendahnya keterampilan menulis khususnya anekdot siswa kelas X MA swasta Depok, terlihat dari keaktifan siswa pada pembelajaran menulis masih kurang yaitu hanya $40 \%$ siswa yang aktif selama pembelajaran, siswa yang keseluruhan merupakan siswa laki-laki kurang tertarik untuk menulis, siswa sering ter-tukar menempatkan urutan bagian teks berdasarkan struktur, teks yang dihasilkan siswa sering tidak lengkap strukturnya, siswa sulit mencari ide yang menarik. Selain hambatan dari siswa hambatan pencapaian keterampilan menulis teks anekdot juga berasal dari guru, yaitu pembelajaran yang digunakan guru kurang bervariasi sehingga siswa kurang tertarik dalam mengikuti pembelajaran.

Permasalahan tersebut harus diperhatikan karena kemampuan menulis anekdot sangat berperan dalam pembelajaran Bahasa dan Sastra Indonesia. Teks anekdot mempunyai kontribusi yang besar pada pembelajaran keterampilan menulis bentuk-bentuk lainnya. Oleh karena itu, guru sebagai salah satu komponen sentral dalam proses pembelajaran agar proses belajar mengajar dapat berhasil dengan baik dan terlaksana secara optimal. Upaya untuk membantu siswa mengatasi rendahnya keterampilan menulis anekdot, salah satu dapat ditempuh dengan cara meningkatkan penggunaan strategi dalam proses pembelajaran. Praktik menulis anekdot akan dilakukan dengan baik jika 
ada perasaan senang atau tertarik dari siswa terhadap kegiatan menulis tersebut.

Genius Learning adalah strategi pembelajaran yang pada intinya membangun dan mengembangkan lingkungan pembelajaran yang positif dan kondusif. Kondisi kondusif ini merupakan syarat mutlak demi tercapainya hasil belajar yang maksimal. Strategi pembelajaran ini guru harus memberikan kesan bahwa kelas merupakan suatu tempat yang menghargai siswa sebagai seorang manusia yang pemikiran dan idenya dihargai sepenuhnya [3]. Tujuan pembelajaran dengan strategi pembelajaran Genius Learning pada intinya adalah bagaimana membuat proses pembelajaran menjadi efektif, efisien, dan menyenangkan. Dengan penerapan strategi pembelajaran Genius Learning dalam proses belajar, siswa diharapkan tidak hanya mendengar, melainkan juga dapat memahami, melihat dan mempraktikkan secara langsung dalam pembelajaran [4].

Motivasi adalah dorongan diri yang menggerakkan seseorang bertingkah laku. Hal senada dikemukan oleh Nasution bahwa motivasi adalah kondisi psykologis yang mendorong seseorang untuk melakukan sesuatu. Jadi dapat disimpulkan bahwa motivasi itu suatu dorongan, usaha psykologis, tenaga-tenaga yang ditimbul dalam diri seseorang untuk berbuat sesuatu karena adanya keinginan yang hendak dicapai untuk memperoleh kepuasan [5].

Motivasi belajar dapat digolongkan dalam dua kategori yaitu motivasi instrinsik dan motivasi ekstrinsik. Sehubungan dengan hal tersebut Sardiman, menyatakan bahwa motivasi instristik adalah motif-motif yang menjadi aktif atau berfungsinya tidak perlu dirangsang dari luar, karena dari dalam diri seseorang sudah ada dorongan untuk melakukan sesuatu, sedangkan motivasi eksrinsik adalah motif-motif yang aktif dan berfungsinya karena adanya perangsang dari luar [6].

Menurut Wachidah teks anekdot memuat hal yang bersifat humor atau lucu [7]. Sedangkan Danandjaya mendefinisikan anekdot sebagai dongeng yang dapat menimbul-kan rasa menggelikan hati, sehingga dapat menimbulkan tawa bagi yang mendengar maupun yang menceritakannya. Senada dengan pernyataan tersebut, Keraf mengemukakan bahwa anekdot adalah semacam cerita pendek yang bertujuan menyampaikan karakteristik yang menarik atau aneh mengenai seseorang atau suatu hal yang lain. Sementara itu, Chaer menuliskan bahwa anekdot adalah cerita singkat yang lucu mengenai seorang tokoh terkenal, yang ada atau pernah ada. Tokoh dalam anekdot bukan tokoh fiktif, melainkan tokoh nyata yang ada dalam sejarah [8].

Dalam penelitian ini dituliskan proses menulis anekdot untuk siswa kelas X MA swasta di Depok. Kegiatan menulis anekdot tersebut membutuhkan pengetahuan kebahasaan, keterampilan berbahasa dan penguasaan kosakata. Berbekal ketiga itu, siswa diharapkan dapat menghasilkan tulisan yang baik dengan kriteria antara lain: bermakna, jelas, merupakan kesatuan yang bulat, singkat, dan padat, serta memenuhi kaidah kebahasaan. Berdasarkan latar belakang masalah itu di atas, melalui penelitian ini akan diterapkan motivasi dan strategi metode pembelajaran untuk meningkatkan kemampuan menulis anekdot siswa kelas $\mathrm{X}$ MA swasta Depok melalui metode pembelajaran ini diharapkan dapat meningkatkan kemampuan menulis anekdot siswa. 


\section{METODE}

Metode penelitian ini adalah kuantitatif yaitu cara atau prosedur untuk mendapatkan data yang digunakan untuk penemuan, pengembangan berdasarkan kaidah ilmu pengetahuan, dan metode pengumpulan yang digunakan dalam penelitian ini adalah Field Research (penelitian lapangan). Penelitian menggunakan 3 (tiga) buah instrumental yang berbentuk kuesioner yang disusun berdasarkan indikator-indikator yang ada dalam variabel penelitian untuk mengukur masing-masing: kemampuan menulis teks anekdot sebagai variabel terikat, motivasi belajar sebagai variabel bebas, dan metode pemebelajaran sebagai variabel bebas. Paradigma penelitian yang menghubungkan antara variabel motivasi belajar dan metode pembelajaran dengan variabel kemampuan menulis teks anekdot.

Populasi dalam penelitian ini adalah seluruh siswa kelas X MA Nur Al Zahrah dan MA Al Jihad pada tahun ajaran 20162017, dimana kapasitas tiap kelas 34-40 siswa.Dari populasi yang ada ini, yang menjadi populasi terjangkau adalah 2 kelas yaitu kelas X MA Nur Al Zahrah yang berjumlah 37 siswa, dan kelas X MA Al Jihad yang berjumlah 34 siswa, jadi jumlah keseluruhan 71 siswa.

Untuk memudahkan penelitian dan pengambilan data maka perlu adanya batasan terhadap populasi yang diambil dengan cara menarik sampel. Pengambilan sampel yaitu undian (jumlah kelas paralel dari sekolah yang dijadikan populasi), setiap kertas undian tertulis nama kelas paralel dan sekolah populasi. Undian yang keluar yang akan menjadi sampel MA Nur Al Zahrah kelas X-1 dan MA Al Jihad X-3 jadi besarnya sampel adalah : 25/100 x $260=65$ siswa.

Namun demikian karena pertimbangan yang akan menjadi sampel yaitu MA Nur
Al Zahrah kelas X-1 berjumlah 37 siswa dan MA Al Jihad kelas X-3 berjumlah 34 siswa dan semakin banyak sampel semakin baik maka untuk penelitian jumlah ini akan digenapkan menjadi 71 siswa ( 2 Kelas) jumlah ini secara keseluruhan sudah mengambarkan pengambilan sampel secara random atau acak.

Teknik pengumpulan data pada masingmasing variabel yaitu untuk motivasi belajar menggunakan angket, metode belajar beruta treatment dan kemampuan menulis anekdot dengan menggunakan instrumen tes.

\section{HASIL DAN PEMBAHASAN}

Penelitian ini merupakan penelitian yang terdiri dari dua faktor bebas, yaitu faktor metode pembelajaran (A) dan motivasi belajar (B). masing-masing faktor terdiri dari sub faktor yang disebut level. Untuk metode pembelajaran (A) ada dua level, yaitu Genius Learning (A1) dan konvensional (A2). Faktor kedua motivasi belajar (B) dengan dua level, yaitu : tinggi (B1) dan rendah (B2).

Data kemampuan menulis teks anekdot siswa yang menggunakan metode pembelajaran genuis learning (A1). Data kemampuan menulis teks anekdot siswa yang menggunakan metode pembelajaran genius learning diperoleh dari nilai tes responden yang menjadi sampel penelitian sebanyak 37 siswa. Nilai yang di peroleh adalah terendah 65 , skor tertinggi 95 , skor rata-rata sebesar 80.95 .

Data Kemampuan menulis anekdot siswa yang menggunakan metode pembelajaran konvensional (A2). Data kemampuan menulis teks anekdot siswa yang menggunakan metode pembelajaran konvensional diperoleh dari nilai tes respondenyang menjadi sampel penelitian sebanyak 37 siswa. Nilai yang diperoleh 
adalah terendah 65 , skor tertinggi 95 , skor rata-rata 76.76.

Data Kemampuan Menulis Anekdot Siswa yang Memiliki Motivasi Belajar Tinggi (B1). Data kemampuan menulis teks anekdot siswa yang memiliki motivasi belajar tinggi, diperoleh dari nilai tes responden yang menjadi sampel penelitian sebanyak 37 siswa. Nilai yang diperoleh adalah terendah 65 , skor tertinggi 95 , skor rata-rata sebesar 82.70 .

Data Kemampuan Menulis Teks Anekdot Siswa yang Memiliki Motivasi Belajar Rendah (B2). Data kemampuan menulis teks anekdot siswa yang memiliki motivasi belajar rendah diperoleh dari nilai tes responden yang menjadi sampel penelitian sebanyak 37 siswa. Nilai yang di peroleh adalah terendah 65 , skor tertinggi 95 , skor rata-rata sebesar 75.00.

Kegiatan pembelajaran yang dilakukan oleg guru dikelas dalam mengasah kemampuan siswa untuk menulis anekdot merupakan salah satu nya diterapkan dengan metode pembelajaran genius learning. Hal ini telah diteliti sebelumya dapat meningkatkan kemampuan siswa dalam menulis anekdot dalam pembelajaran bahasa Indonesia.

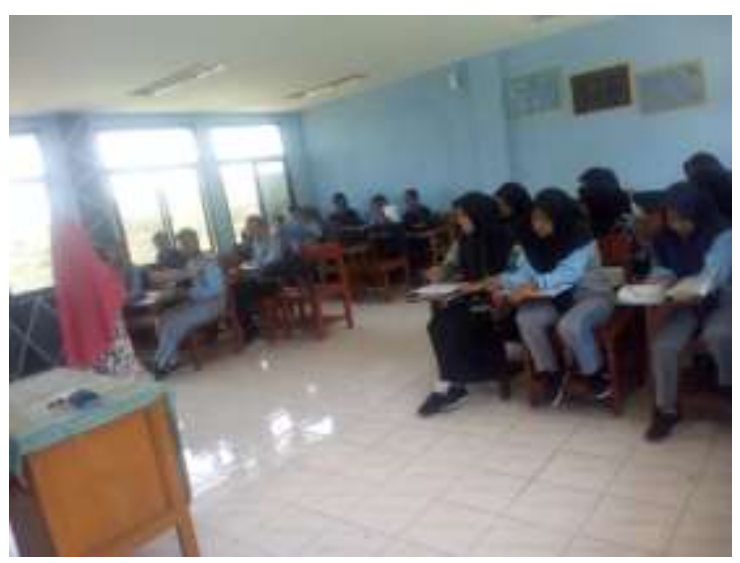

Gambar 1: Suasana Kegiatan Pembelajaran
Kegiatan pembelajaran yang dilukan dikelas menunjang untuk mengasah keterampilan bagaimana siswa dapat mengaplikasikan anekdot dan menuliskannya sehingga dapat menjadi salah satu indikator keberhasilan pembelajaran yang dilakukan dikelas.

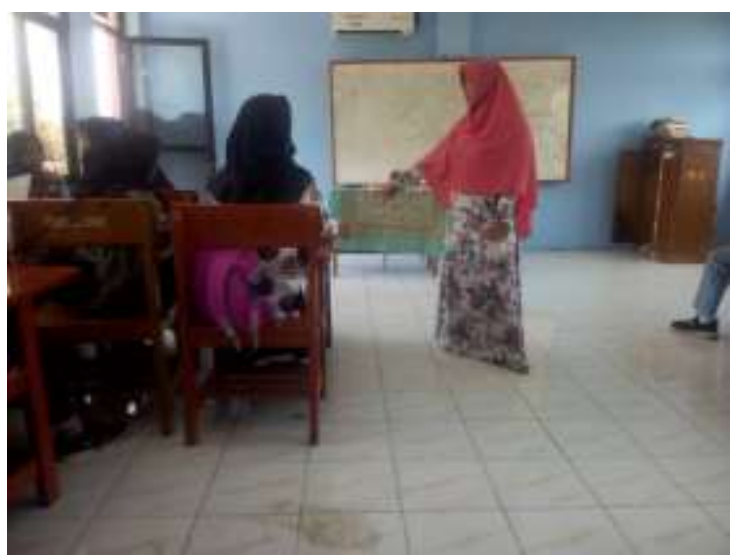

Gambar 2: Guru Sedang Memberikan Arahan

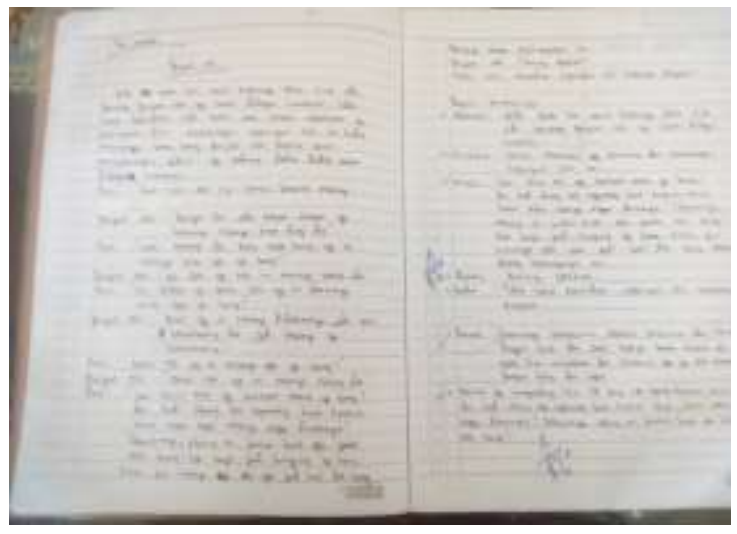

Gambar 3. Hasil Tes Kemampuan Siswa

\section{SIMPULAN}

Keterampilan menulis teks anekdot menggunakan metode Pembelajaran genius learning mengalami peningkatan dari pada menggunakan metode konvensional. Peningkatan tersebut dapat diketahui dari kondisi siswa di kelas selama pembelajaran berlangsung. Dengan memberikan motivasi yang tinggi dalam 
proses pembelajaran menulis teks anekdot juga ikut mempengaruhi peningkatan hasil keterampilan siswa dalam menulis teks anekdot. Peneliti memberikan saran kepada guru bahasa Indonesia agar menggunakan metode pembelajaran genius learning sebagai alteratif penggunaan metode pembelajaran yang terbukti meningatkan keterampilan siswa dalam menulis teks anekdot dan merubah perilaku siswa lebih semangat dalam belajar. Sedangkan peneliti lain, penelitian ini dapat digunakan sebagai pembanding dalam melakukan penelitian lainnya sebagai upaya meningkatkan keterampilan menulis teks anekdot dengan menggunakan pendekatan, strategi, model, metode, maupun teknik yang berbeda.

\section{DAFTAR PUSTAKA}

[1] Sutama. Metode penelitian pendidikan. Surakarta: Penerbit Setiaji. 2000.

[2] Asmani, J. M. Buku panduan internalisasi pendidikan karakter di sekolah. Yogyakarta: DIVA Press. 2011.

[3] Gunawan, A. W. Genius learning strategy. Jakarta: PT Gramedia. 2013.

[4] Penerapan Metode Genius Learning Terhadap Hasil Belajar Siswa pada Mata Pelajaran Sejarah Kebudayaan Islam di MIN 1 Teladan Palembang

[5] Uno. H.B. Teori Motivasi dan Pengukurannya: analisis di bidang pendidikan. Jakarta : Bumi Aksara. 2012.

[6] Pengaruh Motivasi Belajar Terhadap Prestasi Belajar The Influence of study motivation through students' study achievement in student of class XI IPS at SMA Negeri 2 Metro Academic year 2012/2013

[7] Wachidah.S. Pembelajaran Teks Anekdot. Jakarta: Departemen Pendidikan Nasional Direktorat Jenderal Pendidikan Dasar dan
Menengah Direktorat Pendidikan Lanjut Pertama. 2004.

[8] Peningkatan Keterampilan Menulis Teks Anekdot Bermuatan Kesantunan Berbahasa Menggunakan Model Pembelajaran Berbasis Masalah (Problem Based Learning) pada Siswa Kelas X MIA - 4 SMA Negeri Grobogan Tahun Ajaran 2013-2014 